Antonio Espuña, Moisès Graells and Luis Puigjaner (Editors), Proceedings of the $27^{\text {th }}$ European Symposium on Computer Aided Process Engineering - ESCAPE 27

October $1^{\text {st }}-5^{\text {th }}, 2017$, Barcelona, Spain (C) 2017 Elsevier B.V. All rights reserved.

\title{
A Hybrid Methodology for Combined Interplant Heat, Water, and Power Integration
}

\author{
Maziar Kermani $^{\mathrm{a}^{*}}$, A.S. Wallerand ${ }^{\mathrm{a}}$, Ivan Kantor ${ }^{\mathrm{a}}$ and François Maréchal ${ }^{\mathrm{a}}$ \\ ${ }^{a}$ École Polytechnique Fédéral de Lausanne (EPFL), IPESE group, Sion, Switzerland \\ maziar.kermani@epfl.ch
}

\begin{abstract}
The growing desire to improve resource efficiency and environmental impact of industrial processes is directly linked to optimal management of heat, mass and power flows. The concept of industrial symbiosis tackles this issue by proposing interplant heat recovery and resource transfer which can bring economical and environmental benefits to each party. A comprehensive methodology is required which can easily be incorporated in the planning of industrial clusters. Therefore, a generic hybrid mixed integer linear programming superstructure has been developed to address simultaneous heat, water, and power optimization in interplant operations. Additional concepts are included in the previouslyproposed water network superstructure (Kermani et al., 2017) to account for the issues related to interplant heat and mass exchange. A cold utility superstructure is included in the water network while a steam network superstructure is modified to better represent the feedwater heaters and heat recovery opportunities. The proposed methodology is applied to an industrial case study. Results exhibit a large potential for synergies among industrial sites, even in disparate sectors, and emphasize the importance of a generic approach.
\end{abstract}

Keywords: linear programming; superstructure optimization; industrial symbiosis;

\section{Introduction}

Energy and water are essential to all industrial processes. Water serves as production support and as a main constituent in some manufactured goods (e.g. beverages). Steam is used as a heating medium and can also be used directly within the process (e.g. steam stripping). Water, in its liquid and vapor phases, is thus a ubiquitous energy carrier and acts as an intermediate heat transfer medium at different temperature levels. Steam can also be used in a Rankine cycle to produce electricity. These complex interactions accentuate the strong interconnectivity of water and energy and the necessity of their simultaneous consideration to improve efficiency and hence reduce the environmental impact of industrial processes. These interactions exhibit even stronger significance in interplant operations in which waste heat/resources of one plant can be recycled or reused in others. Although heat-integrated water allocation networks have been extensively studied in recent years (Ahmetović et al., 2015), few authors have proposed interplant methodologies (Zhou et al., 2012b,a) and those that do are limited to water recovery in interplant operations without heat recovery since they do not consider process non-water thermal streams. Interplant heat recovery has also been extensively addressed in the literature as part of "total site heat integration" (TSHI) methodologies (Klemeš et al., 1997). Liew et al. (2017) provides a comprehensive overview of conceptual and mathematical methodologies with emphasis on inter-process (interplant) direct and indirect heat integration. Mathemat- 
ical methodologies are based on superstructure optimization approaches and generally make use of mixed integer non-linear programming (MINLP). They have the possibility of finding the global optimum to the problem, however, lack the insights that are inherent to conceptual methods, are difficult to solve and cannot be easily applied to real industrial cases. Conceptual methods, on the other hand, cannot handle large problem sizes. These considerations emphasize the need for a hybrid methodology that can benefit from both mathematical and conceptual methods. In summary of the aforementioned research directions, Liew et al. (2017) proposed the current gaps in this domain:

1. Development of methodologies for total site heat and power integration,

2. Incorporation of sustainability and environmental criteria,

3. Optimal design of hot water and hot oil loops,

4. Development of multi-period, multi-objective methodologies,

5. Prioritizing hybrid methodologies to overcome the main weakness of mathematical approaches by incorporating industrial insights.

As the result, the aim of the current research is to address these gaps $(1,3,5)$ by proposing a hybrid MILP superstructure for simultaneous optimization of heat, water, and power in interplant operations.

\section{Methodology}

The proposed methodology is formulated as a mixed integer linear programming (MILP) superstructure which is based on the previous work of (Kermani et al., 2017). Given is a set $\mathbf{P}$ of industrial sites (or clusters within each plant). Each site $i$ has a set of water unit operations (demands: $\mathbf{W}_{i}^{d}$, sources: $\mathbf{W}_{i}^{s}$ ) and set of process thermal streams (hot: $\mathbf{S}_{i}^{h}$, cold: $\mathbf{S}_{i}^{c}$ ). Several fresh water sources at different temperatures and qualities and waste water sinks at different temperatures and disposal qualities are available. In order to address the interplant combined heat, water, and power optimization, the methodology is extended to incorporate thermal utilities. The objective is to minimize the total annualized cost of the system including the operating cost of the thermal utilities and water consumption together with investment cost subject to heat cascade constraints (Maréchal and Kalitventzeff, 1996) and water network constraints (Kermani et al., 2017). Figure 1 encapsulates the major elements of the proposed generic superstructure.

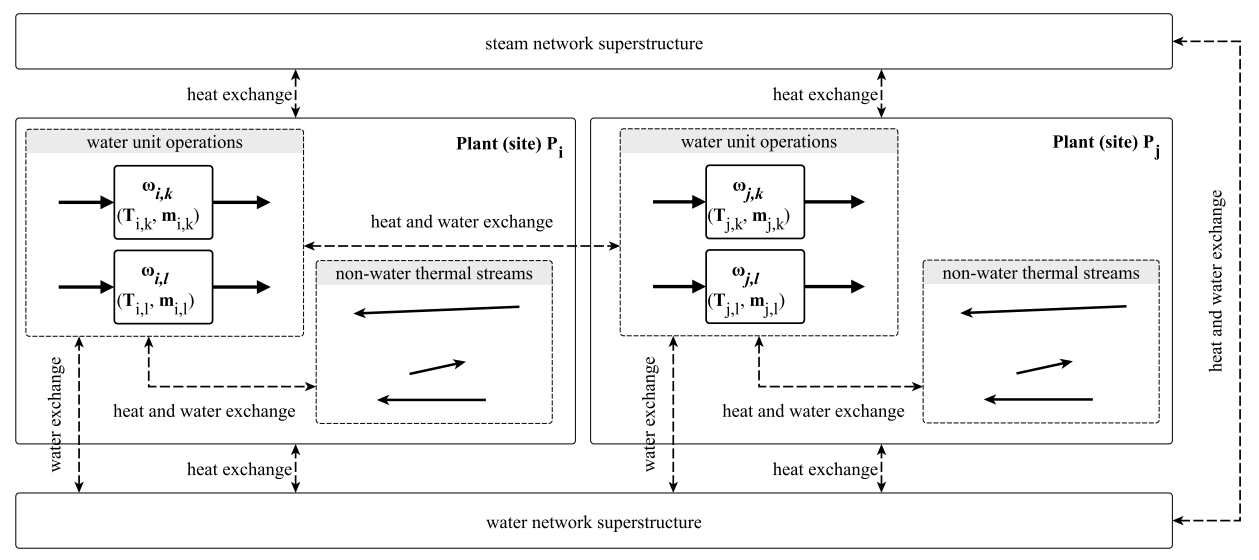

Figure 1: Schematic of the proposed mathematical superstructure 


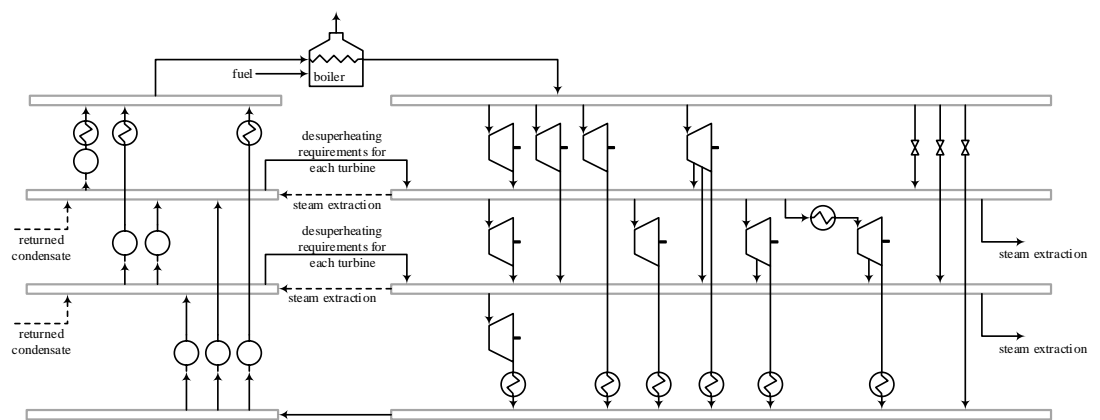

Figure 2: The proposed steam network superstructure

Water network superstructure: The water network superstructure is based on the source-sink representation (Kermani et al., 2017) and is extended to include the cold utility superstructure. Cooling water and process water are distinguished through introducing binary parameters which permit/forbid mixing. As proposed by Kermani et al. (2017), each thermal stream generated in the water network superstructure is assigned a penalizing cost which is proportional to its heat load. It is constructed by linearization of the investment cost of a fictitious heat exchanger to which the water stream belongs. Thermal water tanks are modeled as mixers/splitters at predefined temperature levels (initially a plant-specific constraint).

Combined heat and power superstructure: The steam network superstructure is based on the work of Maréchal and Kalitventzeff (1999). The model was improved by addition of different types of feedwater heaters and pumping equipment between any two pressure levels to provide more options for the returning condensate streams. In addition, the investment cost of turbines, pumps, and boilers are included in the superstructure. This is necessary in combined heat and power optimization approaches to analyze the worthiness of extra investment in the power generation system as opposed to producing steam at required pressure levels through heat recovery. It should be noted that the superstructure is capable of producing steam at all the pressure levels which is conventional in TSHI methodologies. However, this is not realistic and will lead to an excessively undersized utility system. In all cases treated here, steam can therefore only be produced at the highest pressure level and any demand of steam at lower levels can be satisfied using a turbine or a letdown unit. The difference lies in the economic viability of electricity generation. Figure 2 illustrates the proposed superstructure.

Solution strategy: For industrial case studies, the size of the mathematical superstructure can become very large. To overcome this issue and to incorporate industrial specificities, a hybrid methodology is applied in which it is required to implement practical and feasibility constraints a priori. This necessitates communication with industrial experts and the understanding of the processes involved. As a general practical constraint, no heat exchange is allowed between plants except by using the water or steam network as intermediaries. In addition, geographical and physical constraints in interplant mass and heat exchange are imposed through the concept of forbidden matches (Papoulias and Grossmann, 1983). Furthermore, the associated linearized costs of water thermal streams depend on the points between which the linearization is performed which will affect the solution. As a result, a two-step solution strategy is proposed: first, the MILP model is solved to minimize the utility consumption without penalty costs. In a second step, the 
Table 1: Operating data for the interplant case study

\begin{tabular}{|c|c|c|c|c|c|c|c|}
\hline Water units & $T_{\text {in }}\left[{ }^{\circ} \mathrm{C}\right]$ & $T_{\text {out }}\left[{ }^{\circ} \mathrm{C}\right]$ & flow $[\mathrm{kg} / \mathrm{s}]$ & Process units & $T_{\text {in }}\left[{ }^{\circ} \mathrm{C}\right]$ & $T_{\text {out }}\left[{ }^{\circ} \mathrm{C}\right]$ & heat load $[\mathrm{kW}]$ \\
\hline \multicolumn{8}{|c|}{ Petrochemical industry (PC) } \\
\hline$A_{1}$ & 40 & 54.5 & 60 & $A_{9}^{h}$ & 91 & 54 & 3,290 \\
\hline$A_{2}$ & 25 & 43.6 & 63.2 & $D_{2}^{h}$ & 77 & 6 & 3,820 \\
\hline$B_{1}$ & 15 & 72.1 & 50 & $D_{3}^{h}$ & 93 & 4 & 4,620 \\
\hline$B_{6}$ & 30 & 41.0 & 159 & $A_{7}^{c}$ & 25 & 60 & 7,830 \\
\hline$C_{1}$ & 15 & 25.9 & 112.2 & $A_{8}^{c}$ & 31 & 79 & 4,960 \\
\hline$C_{3}$ & 15 & 46.8 & 31.9 & $B_{7}^{c}$ & 50 & 66 & 3,310 \\
\hline \multicolumn{8}{|c|}{ Pulp and paper industry (PP) } \\
\hline pulp machine & 50 & 50 & 10 & $P P_{1}^{h}$ & 65 & 64 & 7,560 \\
\hline bleaching & 70 & 70 & 20 & $P P_{2}^{h}$ & 95 & 50 & 10,920 \\
\hline washing & 65 & 65 & 35 & $P P_{3}^{h}$ & 75 & 40 & 2,205 \\
\hline stock preparation & 62 & 62 & 25 & $P P_{4}^{h}$ & 59 & 30 & 1,050 \\
\hline recausticization & 35 & 35 & 20 & $P P_{5}^{h}$ & 80 & 65 & 630 \\
\hline
\end{tabular}

(a) Fresh water temperature is $15^{\circ} \mathrm{C}$. Waste water disposal temperature is $30^{\circ} \mathrm{C}$. Refrigeration is available at $-10^{\circ} \mathrm{C}$.

(b) Forbidden matches in pulp and paper industry are given in (Kermani et al, 2017).

(d) Forbidden matches in petrochemical industry: Outlet of $A_{1}, A_{2}$, and $B_{6}$ cannot be mixed in tanks. However they can be recycled in the processes.

solution of the first step becomes the upper bound in the problem which is then formulated to minimize the total annualized cost of the system.

\section{Interplant case study}

The proposed methodology was evaluated using a case study encompassing two industrial plants: petrochemical and pulp \& paper. Water unit operations and thermal process streams are shown in Table 1. One water tank is available in the petrochemical site $\left(60{ }^{\circ} \mathrm{C}\right)$ and two are available in the pulp \& paper site $\left(35^{\circ} \mathrm{C}, 62^{\circ} \mathrm{C}\right)$. The steam network superstructure is not addressed in this case due to low temperature levels in the system. The results are analyzed based on

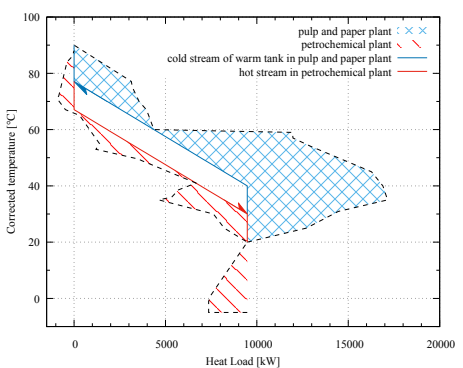

Figure 3: Integrated grand composite curve for the optimized interplant case study energy and water consumption and total annualized cost.

Heat integration analysis had not been applied to either plant for the "Business-asusual" (BAU) case, and therefore, separate optimization of the two independent plants showed dramatic reductions in the costs and resource consumptions (Table 2). Applying

Table 2: Results of the interplant case study

\begin{tabular}{|c|c|c|c|c|c|c|c|}
\hline & \multicolumn{2}{|c|}{ Petrochemical Plant } & \multicolumn{2}{|c|}{ Pulp \& Paper Plant } & \multicolumn{2}{|c|}{ Two Plants } & \multirow[t]{2}{*}{ Proposed Approach } \\
\hline & BAU (1) & SOWE (2) & BAU & SOWE & BAU & SOWE & \\
\hline Hot utility (3) [kW] & 44,291 & 7,215 & 3,392 & 0 & 47,683 & 7,215 & 0 \\
\hline Cold utility $(4)[\mathrm{kW}]$ & 29,595 & - & 14,270 & - & 43,864 & - & - \\
\hline Refrigeration $(5)[\mathrm{kW}]$ & 8,440 & 2,112 & - & - & 8,440 & 2,112 & 2,112 \\
\hline Fresh water-wastewater $[\mathrm{kg} / \mathrm{s}]$ & 476.3 & - & 137 & - & 613.3 & - & - \\
\hline Total water consumption $(6)[\mathrm{kg} / \mathrm{s}]$ & 946 & 457.7 & 363.3 & 355 & 1,310 & 813 & 698 \\
\hline Operating cost [USD/y] & $13,867,500$ & $3,923,100$ & $2,283,100$ & $1,707,300$ & $16,150,600$ & $5,630,400$ & $3,942,000$ \\
\hline Investment cost (7) [USD/y] & 0 & 603,400 & 0 & 255,230 & 0 & 858,630 & $1,066,200$ \\
\hline Total cost [USD/y] & $13,867,500$ & $4,526,500$ & $2,283,100$ & $1,962,530$ & $16,150,600$ & $6,489,030$ & $5,008,200$ \\
\hline $\begin{array}{l}1 \text { - Business as Usual } \\
2 \text { - Simultaneous Optimization of Water an } \\
3 \text { - Steam at } 2 \text { bar } \\
4 \text { - The amount of fresh water to cool down } \\
5 \text { - In BAU: Streams } D_{2}^{h} \text { and } D_{3}^{h} \text { are coolec } \\
6 \text { - Including all the water consumption in }\end{array}$ & $\begin{array}{l}\text { Energy (SOWE } \\
\text { the waste stream } \\
\text { down by refriger } \\
\text { e system (in BA }\end{array}$ & $\begin{array}{l}\text { methodology } \\
\text { to } 30^{\circ} \mathrm{C} \text { in } \mathrm{B} \text {. } \\
\text { tion cycle. } \\
\mathrm{J} \text { the cooling w }\end{array}$ & nani et al., 20 & & & & \\
\hline
\end{tabular}




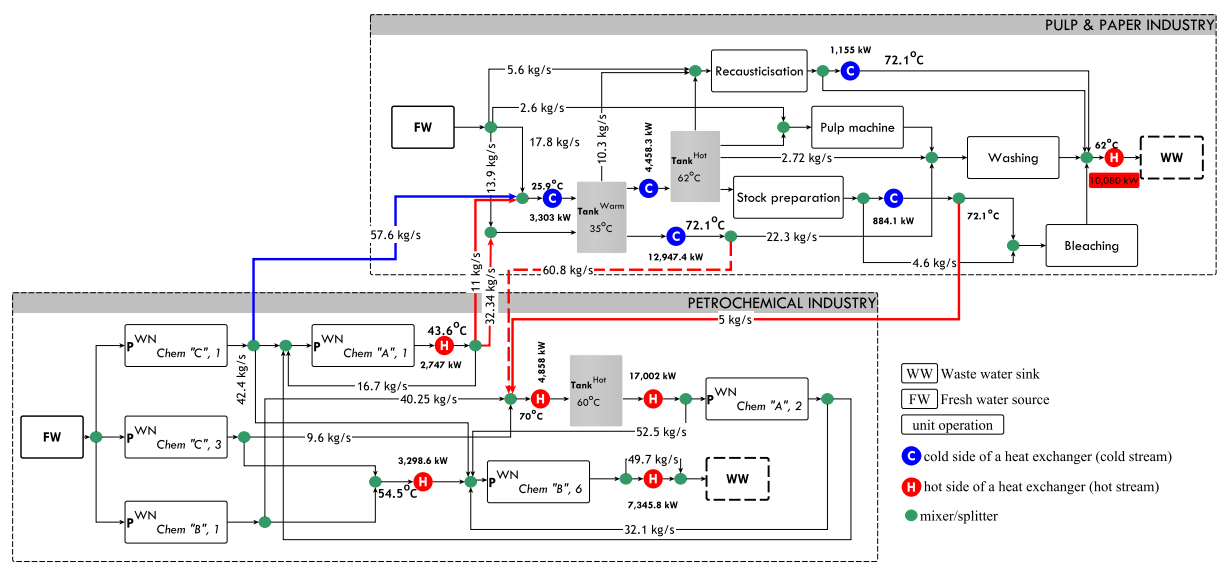

Figure 4: Optimal heat-integrated water allocation network for the interplant case study

the proposed methodology eliminated the hot utility and further reduced the total water consumption by $14 \%$. The total cost was consequently reduced by $23 \%$. Figure 3 demonstrates how a water thermal stream is exchanging heat between the two industrial clusters. Figure 4 shows the optimal heat-integrated water network using the proposed methodology. The results indicate large potential for synergies between industrial sites.

\section{Pulp \& paper case study}

The proposed methodology is applied to a real kraft mill (Kermani et al., 2017). Three industrial clusters are defined in order to model the geographical constraints of the mill. The water network and steam network superstructures are included in each cluster (no heat exchange takes place between the clusters except via water or steam flows):

- Cluster 1: pulp machine, bleaching, washing, $\mathrm{ClO}_{2}$ production sections.

- Cluster 2: digester and recauticizing sections.

- Cluster 3: evaporation, concentration and stripping sections.

In each cluster, due to physical, thermodynamic and insight-based constraints, several forbidden matches of type heat/mass are imposed. Among others, cooling of equipment (hot thermal stream) should be carried out in the water network even if there exists a feasible cold process thermal stream that can cool down the equipment. Moreover, solid streams (e.g. chips) should be heated up by steam. In the steam network superstructure, steam is produced at 52 bar while it can be consumed at 12, 9, 5, 3 bar (HP, MP, LP, LLP). The condensation level is at 0.07 bar.

The results are compared with the case in which the hot water cycle is not included. In addition, the steam network was modeled a posteriori based on the demand of steam in the combined clusters. The preliminary results are shown in Table 3. It can be observed that the interplant approach decreased the operating cost of the system $(-22 \%)$ while increasing the investment cost $(13 \%)$ which is mainly due to the cost of the heat exchanger network. Reducing the steam production for process demands will decrease the electricity production. 
Table 3: Results of the pulp \& paper case study

\begin{tabular}{|c|c|c|c|}
\hline & & Traditional approach $^{1}$ & Proposed approach \\
\hline HP steam [12 bar] & $\mathrm{kW}$ & - & - \\
\hline MP steam [9 bar] & $\mathrm{kW}$ & 10,187 & 10,187 \\
\hline LP steam [5 bar] & $\mathrm{kW}$ & 32,532 & 32,532 \\
\hline LLP steam [3 bar] & $\mathrm{kW}$ & 49,520 & 32,284 \\
\hline Fresh water & $\mathrm{kg} / \mathrm{s}$ & 1,005 & 594 \\
\hline Waste water & $\mathrm{kg} / \mathrm{s}$ & 1,060 & 649 \\
\hline Electricity & $\mathrm{kW}$ & 22,898 & 18,154 \\
\hline Investment cost & USD/y & $5,872,000$ & $6,683,000$ \\
\hline Operating cost & $\mathrm{USD} / \mathrm{y}$ & $27,056,900$ & $20,950,000$ \\
\hline Selling of electricity ${ }^{2}$ & USD/y & $-13,199,500$ & $-10,464,700$ \\
\hline Total cost & USD/y & $19,729,400$ & $17,168,300$ \\
\hline
\end{tabular}

2 - Selling price of electricity is assumed to be $0.07 U S D / k W$

\section{Concluding remarks}

A hybrid mathematical superstructure for simultaneous optimization of water and energy was extended to incorporate the thermal utilities (cooling water network, steam network) as intermediate heat transfer media in interplant operations. The method was applied to a real industrial kraft mill which resulted in reduced demand for low pressure steam and showed more than $40 \%$ reduction in fresh water consumption which highlights the importance of such a combined approach in interplant operations. The potential implications of this work are broad, extending from total site integration to industrial symbiosis. In future work, multi-objective optimization will be performed on the superstructure to optimize the operating conditions of the system (e.g. pressure levels in the steam network, temperatures in the water network).

\section{References}

Ahmetović, E., Ibrić, N., Kravanja, Z., and Grossmann, I. E. (2015). Water and energy integration: A comprehensive literature review of non-isothermal water network synthesis. Computers \& Chemical Engineering, 82:144-171.

Kermani, M., Périn-Levasseur, Z., Benali, M., Savulescu, L., and Maréchal, F. (2017). A novel MILP approach for simultaneous optimization of water and energy: Application to a Canadian softwood Kraft pulping mill. Computers \& Chemical Engineering.

Klemeš, J., Dhole, V. R., Raissi, K., Perry, S. J., and Puigjaner, L. (1997). Targeting and design methodology for reduction of fuel, power and CO2 on total sites. Applied Thermal Engineering, 17(8):993-1003.

Liew, P. Y., Theo, W. L., Wan Alwi, S. R., Lim, J. S., Abdul Manan, Z., Klemeš, J. J., and Varbanov, P. S. (2017). Total Site Heat Integration planning and design for industrial, urban and renewable systems. Renewable and Sustainable Energy Reviews, 68, Part 2:964-985.

Maréchal, F. and Kalitventzeff, B. (1996). Targeting the minimum cost of energy requirements: A new graphical technique for evaluating the integration of utility systems. Computers \& Chemical Engineering, 20, Supplement 1:S225-S230.

Maréchal, F. and Kalitventzeff, B. (1999). Targeting the optimal integration of steam networks: Mathematical tools and methodology. Computers \& Chemical Engineering, 23, Supplement:S133-S136.

Papoulias, S. A. and Grossmann, I. E. (1983). A structural optimization approach in process synthesis-II: Heat recovery networks. Computers \& Chemical Engineering, 7(6):707-721.

Zhou, R.-J., Li, L.-J., Dong, H.-G., and Grossmann, I. E. (2012a). Synthesis of Interplant Water-Allocation and Heat-Exchange Networks. Part 1: Fixed Flow Rate Processes. Industrial \& Engineering Chemistry Research, 51(11):4299-4312.

Zhou, R.-J., Li, L.-J., Dong, H.-G., and Grossmann, I. E. (2012b). Synthesis of Interplant Water-Allocation and Heat-Exchange Networks. Part 2: Integrations between Fixed Flow Rate and Fixed ContaminantLoad Processes. Industrial \& Engineering Chemistry Research, 51(45):14793-14805. 